\title{
Effect of Anisotropy on Unsaturated Hydraulic Conductivity and SWCC of Clayey Soil
}

\author{
Dr. S. I. A. Khatta' Prof. $\quad$ M. N. J. Al-Zaidy' M.Sc. \\ Civ. Engg. Dept. / Mosul Univ.
}

\begin{abstract}
Infiltration of water in unsaturated soils has long been an interest of study in geotechnical engineering. A wide range in permeability coefficient has been proven to be a major obstacle in analyzing seepage problems. Soil-water characteristic curve (SWCC) is a fundamental constitutive relation for the explanation of the engineering behaviour of unsaturated soil. The effect of anisotropy on SWCC and unsaturated coefficients of permeability and diffusion has been studied in this paper, by taking sets of duplicate disturbed and undisturbed specimens prepared in the vertical, $\mathbf{4 5}^{\circ}$ inclined and horizontal directions. The results showed that there is a noticeably anisotropic in the basic characteristics of SWCC and the unsaturated coefficients of permeability and diffusion specially at the low values of suction. The variations of the hydraulic conductivity and vapor diffusivity versus suction gradient were opposite. Furthermore there is a noticeable difference between the disturbed and undisturbed specimens in the SWCC and coefficients of diffusion and permeability.
\end{abstract}

Key words: Anisotropy; directional variation; hydraulic conductivity; soil-water characteristic curve; unsaturated soil.

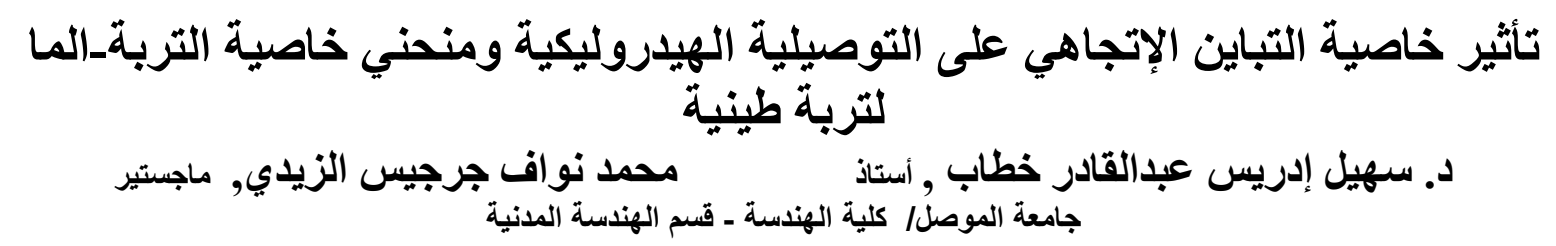

ألخلاصة

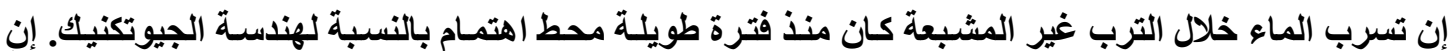

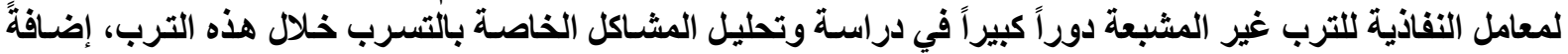

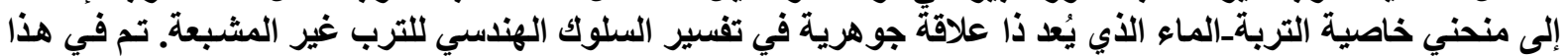

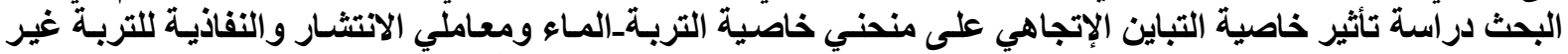

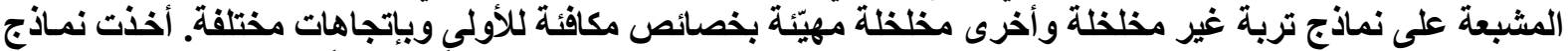

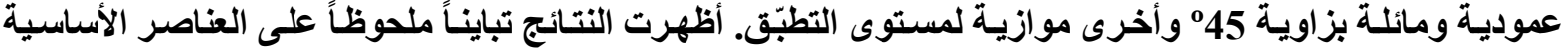

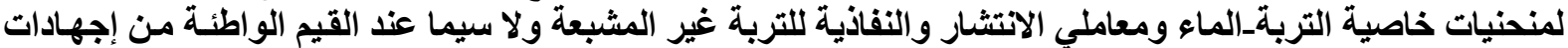

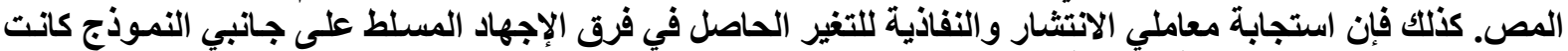

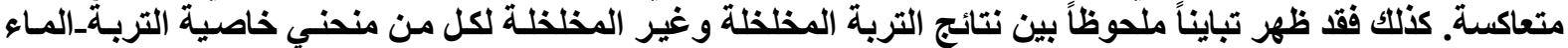

$$
\text { ومعاملي الإنتثار و النفاذية. }
$$




\section{Introduction}

The behaviour of unsaturated soils has become an important topic of modern soil mechanics, because many geotechnical engineering problems are associated with unsaturated soil in arid or semiarid parts of the world [11] and [18]. For example, numerous slope failures occur after a prolonged period of rainfall. These landslides result in the loss of property and even lives. Fills, embankments, and earth dams are typical geotechnical problems related to unsaturated soils. The rise of water table results in a decrease of bearing capacity of building foundation soil. Climatic changes could induce unexpected shrinkage and swelling movements that result in extensive damage to light buildings founded on swelling clays. These practical engineering problems are all involved with the seepage of unsaturated soil. In seepage analysis of unsaturated soil, coefficients of permeability and diffusion are important parameters, because many field problems are analyzed on the basis of soil permeability.

The unsaturated coefficients of permeability and diffusion are not constant like the coefficient of permeability for saturated soil. It can vary widely with the variation of the moisture content of soil. The variation of water content can induce a change of soil suction. The relationship between the soil suction and water content (either gravimetric, $w$, or volumetric, $\theta$, or degree of saturation, $S$ ) is called soil-water characteristic curve. Therefore, the coefficients of permeability and diffusion is often represented by the function of soil suction, and there is a fundamental constitutive relation between the unsaturated coefficients stated above and the soil-water characteristic curve. Several parameters such as compaction water content, stress state, soil structure, mineralogy, texture and organic content influence the soil water characteristic curve behaviour. All the parameters that influence the soil-water characteristic curve behaviour also influence the unsaturated coefficients stated above[18]. One of the most factors that influence the soil water characteristic curve and unsaturated coefficients of permeability and diffusion is the anisotropy [1], which has been studied in this research paper.

Almost soil deposits are often cross-anisotropic in their mechanical and drainage properties, this is due to the preferred horizontal alignment of the solid particles during deposition and subsequent consolidation under the overburden weight [17], [10] \& [16].

\section{Test Programme}

The soil water characteristic curves were measured using two methods, in order to cover the wide range of suction (0-1000000) $\mathrm{kPa}$. Soil specimens of (30) $\mathrm{mm}$ in diameter and (12) $\mathrm{mm}$ in height were prepared for both disturbed and undisturbed. The first method was the osmotic membrane; this method gives matric suctions of the soil between (0-1500) $\mathrm{kPa}$. In this method the soil specimens were put inside the osmotic membrane and soaked in a certain concentration of poly-ethylene glycol (P.E.G.), the membrane allows the moisture movement in one direction only until equilibrium is attained. Al-Taie (2005) [4] recommended that 15 days is sufficient for equilibrium to occur. The final moisture content of the soil specimen is determined and used to obtain the soil suction. This step can be performed with the help of the curve shown in Fig. (1), [14]. The second method is the vapor equilibrium; this method imposes matric suctions of the soil between (1500-400000) $\mathrm{kPa}$. The soil specimens were put inside several desiccators which contain different salt solutions have a known relative humidity and matric suction potential until reaching an equilibrium state of moisture content, Fig. (2). Al-Taie (2005) [4] found that 45 days is sufficient for equilibrium to occur for most types of soil. Table (1) lists the saturated solutions used in this method and it's relative humidity and matric suction. 


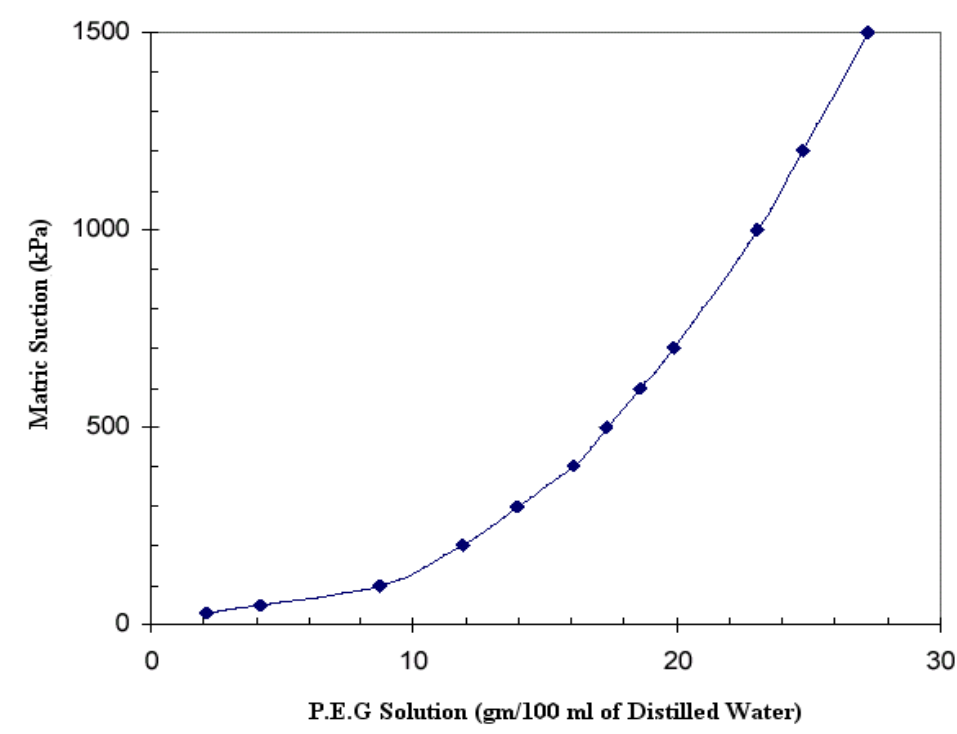

Fig. 1 The calibration curve for the matric suction and the (P.E.G concentrations) [14]

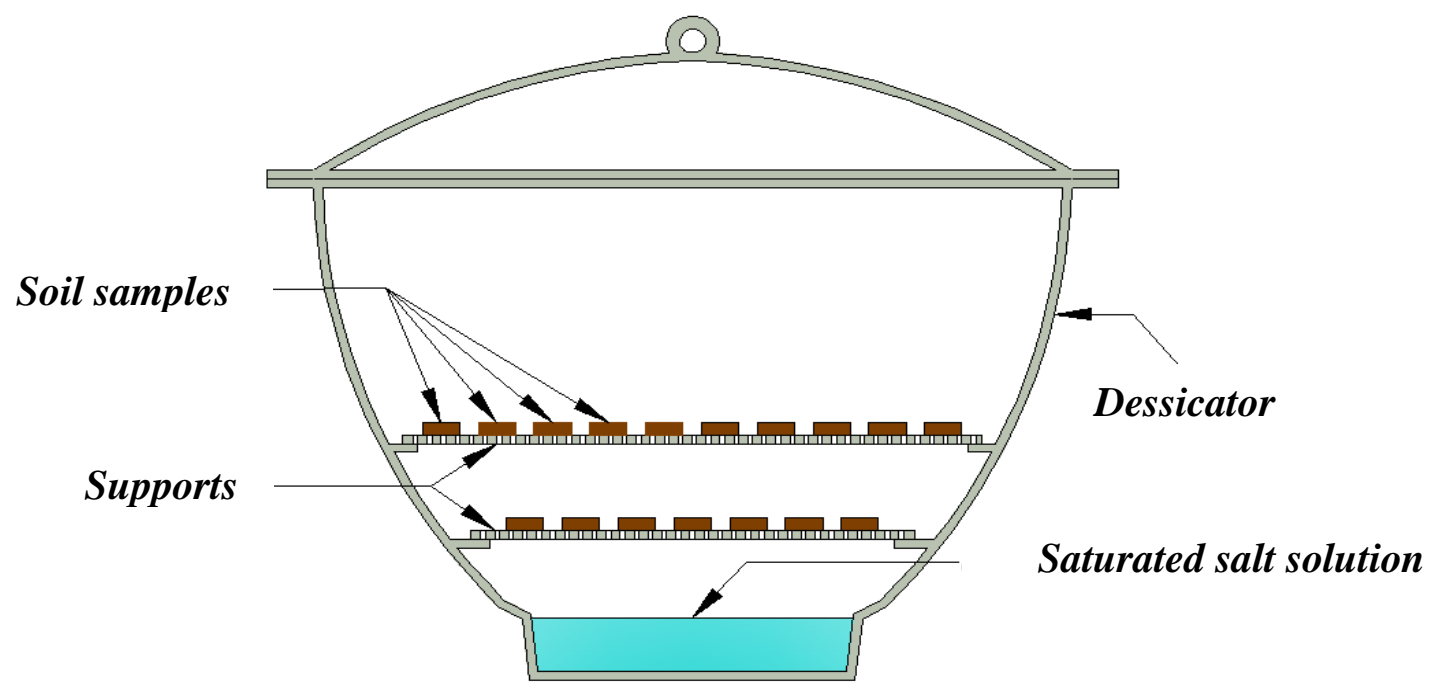

Fig. 2 Dessicator used in the vapor equilibrium method [2]

Table (1): Chemical used in the vapor equilibrium method [4]

\begin{tabular}{|c|c|c|c|}
\hline No. & Chemical Used & $\begin{array}{c}\text { Relative Humidity } \\
\text { (R.H.) } \%\end{array}$ & $\begin{array}{c}\text { Average Matric Suction } \\
\text { at 20-25 }\end{array}$ \\
\hline 1 & $\mathbf{L i C l},(\mathrm{kPa})$
\end{tabular}

This method depends on Kelvin's equation for gas low equation as mentioned by [8]:

$\psi=\frac{R \cdot T}{V} \cdot \ln (R H)$ 
Where:

$\psi=$ Total suction.

$R=$ Universal (molar) gas constant.

$T=$ absolute temperature.

$V=$ specific volume of water at temperature $\mathrm{T}$.

$R . H$. = relative humidity .

When the temperature ( 20 and 25$)^{\circ} \mathrm{C}$ the equation (1) will be:

Total suction $(\mathrm{MPa})=-135.022 \ln (\mathrm{RH}) \quad\left\{@ 20^{\circ} \mathrm{C}\right\}$

Total suction $(\mathrm{MPa})=-137.182 \ln (\mathrm{RH}) \quad\left\{@ 25^{\circ} \mathrm{C}\right\}$

Measurements of the water vapor transfer were carried out using the apparatus shown in Fig. (3) having two cells containing two different saturated salt solutions. Soil samples (with $63.5 \mathrm{~mm}$ in diameter and $19 \mathrm{~mm}$ in height) were placed in the apparatus, the containers of saturated salt solutions were weighed quickly and the cell was rapidly assembled. The salt used in the left cell induces a higher relative humidity than the one used in the right cell. Moisture movement is due to water vapor concentration gradient induced by vapor pressure difference (suction difference) between the two compartments. The water that diffused from the most concentrated zone (left cell) to the less concentrated one (right cell) condenses in the salt solution saturated in the right cell. The increase of the quantity of water is measured with time. All tests were carried out in a controlled room temperature $\left(22 \pm 1^{\circ} \mathrm{C}\right)$. The right container of each cell was weighed every 48 hours over 2 weeks, then twice a week up to the end of the tests (approximately 10 weeks). The water vapor diffusion process continues until an equilibrium state is reached. The data from the experiment will yield the value for the water vapor diffusivity, [6] \& [2]. This procedure is conducted using six diffusion apparatus with different saturated solutions, thus allowing the construction of the complete water vapor diffusivity curve for the tested relative humidity and equivalent suction.

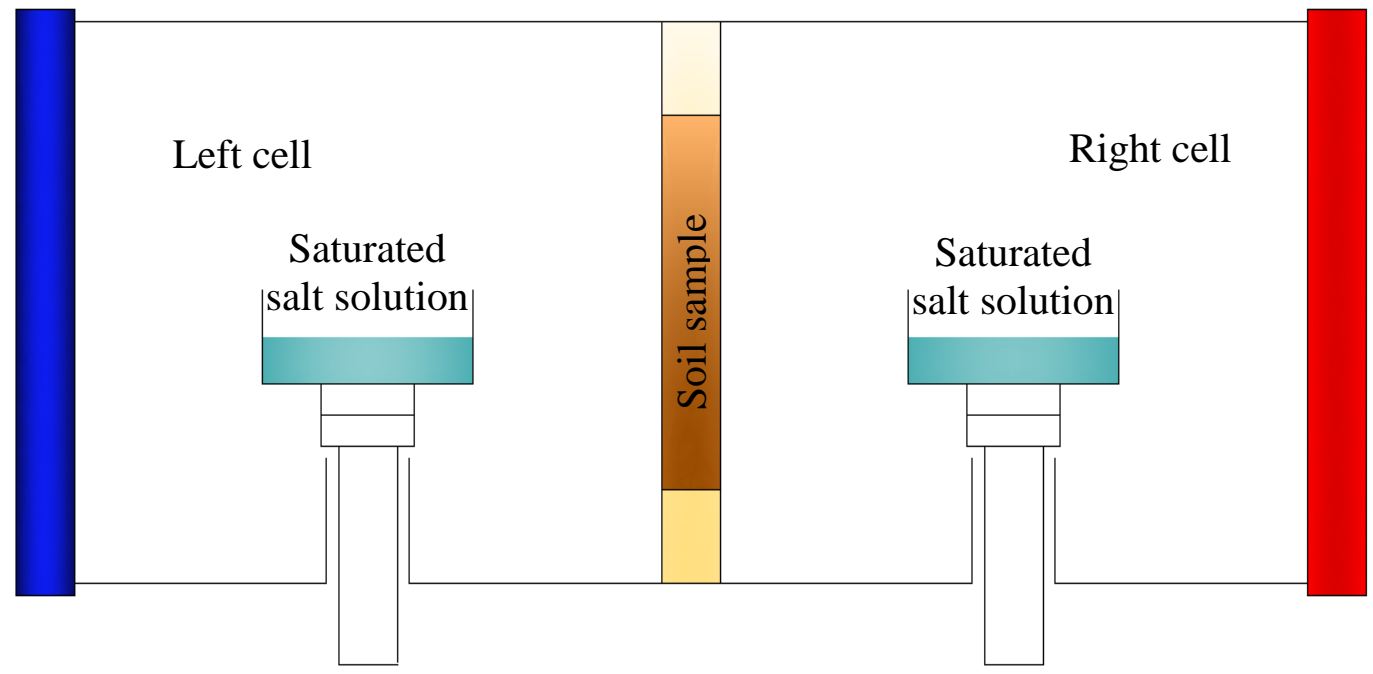

Fig. 3 Apparatus used for determination unsaturated coefficient of permeability and diffusion [2]

Table (2) lists the relative humidity and suction for the different saturated salt solutions for each cell and the corresponding suction gradient. 
Water vapor transfer occurs because of suction gradient and coefficient of permeability and diffusion depend upon the volumetric water content of the sample. The transfer is carried out through the sample thickness due to suction difference applied in the left and right of the sample. Hence, the general flow equation used in such problem is:

$$
\frac{\partial \psi}{\partial t}=\mathrm{D}(\theta) \frac{\partial^{2} \psi}{\partial x^{2}}
$$

Where:

$\mathrm{x}=$ distance moved by water front

$\mathrm{t}=$ time take for water front movement

$\psi=$ Total suction

$D(\theta)=$ water vapor diffusivity

For unsaturated materials, the equation becomes nonlinear. The formula for the calculation of the water vapor diffusivity $D(\theta)$ is:

$\mathrm{D}(\theta)=\mathrm{K}(\theta) \frac{\partial \psi}{\partial \theta}$

Where:

$K(\theta)=$ water vapor permeability $(\mathrm{m} / \mathrm{s})$ as a function of water content.

$\theta=$ volumetric water content

The flow rate was then introduced to Darcy's equation along with the other known variables to calculate the permeability:

$\mathrm{K}(\theta)=\frac{q}{A(\Delta H / l)}$

Where:

$A=$ surface area of tested sample

$l=$ height of the sample

$\Delta \mathrm{H}=$ suction gradient in terms of equivalent height of water $\left(H_{\text {water }} \times \gamma_{\text {water }}\right),[6] \&$ [2].

Table(2): Relative humidity and suction for each cell and suction gradient [2]

\begin{tabular}{|c|c|c|c|c|c|}
\hline No. & $\begin{array}{c}\text { R.H. \% } \\
\text { in left cell }\end{array}$ & $\begin{array}{c}\text { Suction in left } \\
\text { cell }(\mathrm{kPa})\end{array}$ & $\begin{array}{c}\text { R.H. \% } \\
\text { in right cell }\end{array}$ & $\begin{array}{c}\text { Suction in right cell } \\
(\mathrm{kPa})\end{array}$ & $\begin{array}{c}\text { Suction } \\
\text { gradient }(\mathrm{kPa})\end{array}$ \\
\hline 1 & $\mathbf{6 6}$ & $\mathbf{5 6 5 5 2 . 5}$ & $\mathbf{5 5}$ & $\mathbf{8 1 3 6 6 . 8}$ & 24814.3 \\
\hline 2 & $\mathbf{5 5}$ & $\mathbf{8 1 3 6 6 . 8}$ & $\mathbf{3 3}$ & $\mathbf{1 5 0 8 9 1 . 2}$ & 69524.4 \\
\hline 3 & $\mathbf{8 6}$ & $\mathbf{2 0 5 2 7 . 3}$ & $\mathbf{3 3}$ & $\mathbf{1 5 0 8 9 1 . 2}$ & 130363.9 \\
\hline 4 & $\mathbf{3 3}$ & $\mathbf{1 5 0 8 9 1 . 2}$ & $\mathbf{1 2}$ & $\mathbf{2 8 8 5 7 2 . 1}$ & 137680.9 \\
\hline 5 & $\mathbf{9 8}$ & $\mathbf{2 7 4 9 . 5}$ & $\mathbf{3 3}$ & $\mathbf{1 5 0 8 9 1 . 2}$ & 148141.7 \\
\hline 6 & 98 & 2749.5 & 12 & 288572.1 & 285822.6 \\
\hline
\end{tabular}




\section{Investigated materials for this study}

Table (3) lists the description, index and in situ properties of the tested soil obtained from a site in the eastern south of Mosul city illustrated in Fig. (4), at a depth of $2.0 \mathrm{~m}$ in different directions. Fig. (5) Shows the grain size distribution. It can be seen that the soil is a mixture of silt and clay, light reddish in color with a small lumps of $\mathrm{CaCO}_{3}$. The consistency of the tested soil can be described as stiff and it is over consolidated. From the Atterberg limits values shown in table (3), the soil can be classified according to the unified soil classification system as clay with medium plasticity, [5].
Table(3): Description and in situ properties of soil

\begin{tabular}{|c|c|c|}
\hline \multicolumn{2}{|c|}{ Property } & Value \\
\hline \multicolumn{2}{|c|}{ Specific gravity } & $\mathbf{2 . 7 2}$ \\
\hline \multicolumn{2}{|c|}{ Gypsum content \% } & $\mathbf{2 . 2 5}$ \\
\hline \multicolumn{2}{|c|}{ pH value } & $\mathbf{7 . 9 2}$ \\
\hline Grain size analysis & Gravel \% & $\mathbf{3}$ \\
\cline { 2 - 3 } & Sand \% & $\mathbf{8}$ \\
\cline { 2 - 3 } & Silt \% & $\mathbf{5 1}$ \\
\cline { 2 - 3 } & Clay \% & $\mathbf{3 8}$ \\
\hline Atterberg limits & $w_{L} \%$ & $\mathbf{4 6}$ \\
\cline { 2 - 3 } & $w_{P} \%$ & $\mathbf{2 4}$ \\
\cline { 2 - 3 } & $I_{P} \%$ & $\mathbf{2 2}$ \\
\hline In-situe properties & $w_{o} \%$ & $\mathbf{1 6 . 6}$ \\
\cline { 2 - 3 } & $\gamma_{\mathrm{d}} \mathrm{kN} / \mathrm{m}^{3}$ & $\mathbf{1 4 . 6}$ \\
\hline Unified Soil Classification System & $\mathbf{C L}$ \\
\hline
\end{tabular}

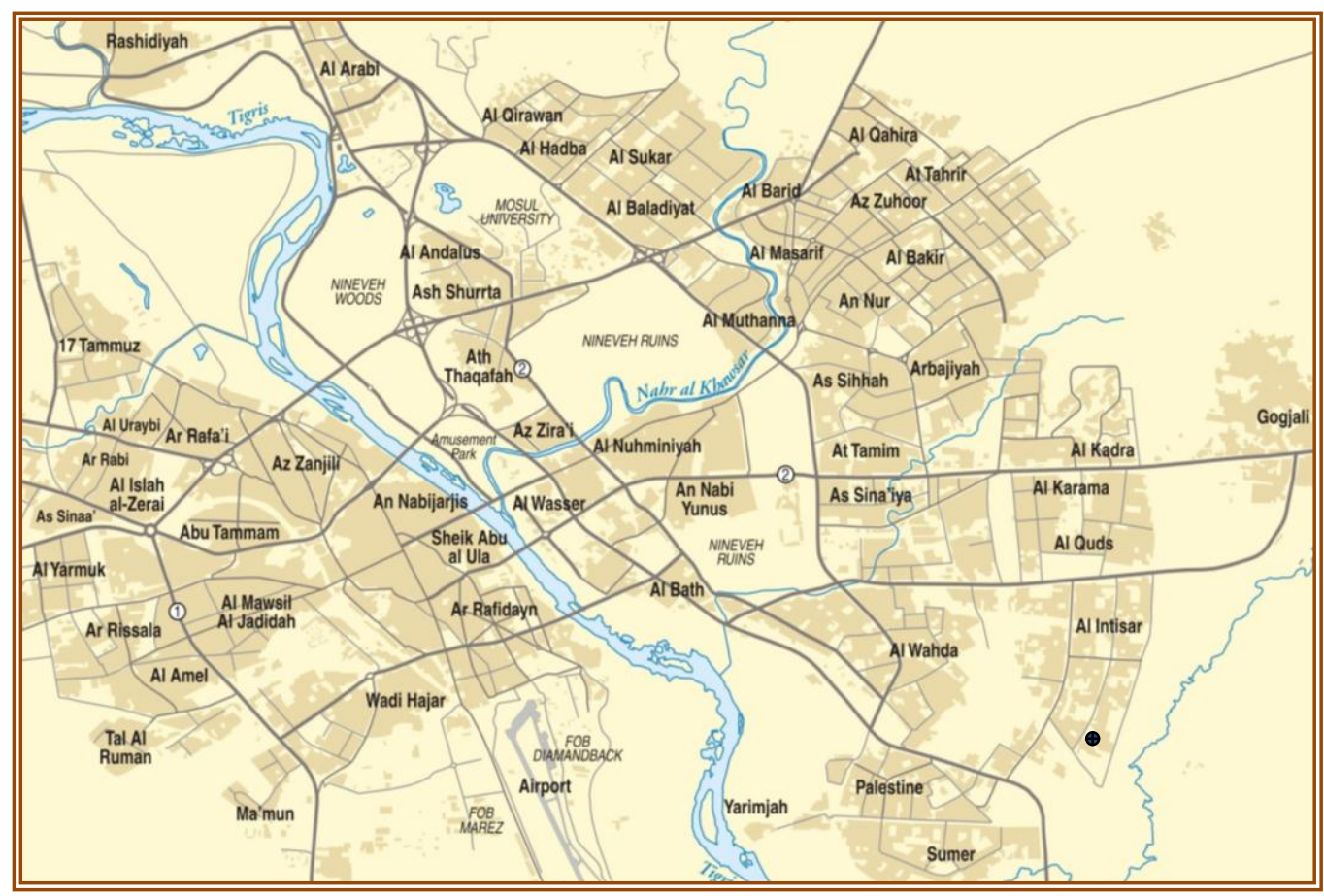

Fig. 4 Location of soil specimens $(\oplus)$

\section{Sample Preparation}

The undisturbed soil specimens were obtained from the site by trimming into stainless steel retaining rings in the three directions (vertical, $45^{\circ}$ inclined and horizontal directions), the lower edge of the ring has a sharp bevel to facilitate the trimming process.

The Compacted soil specimens were prepared in the laboratory from disturbed soil obtained from the same site, The natural soil was cleaned first from undesired materials (such as, brick chip, stone, grass etc.), broken into small pieces, air-dried, reduced into powder by Materials 


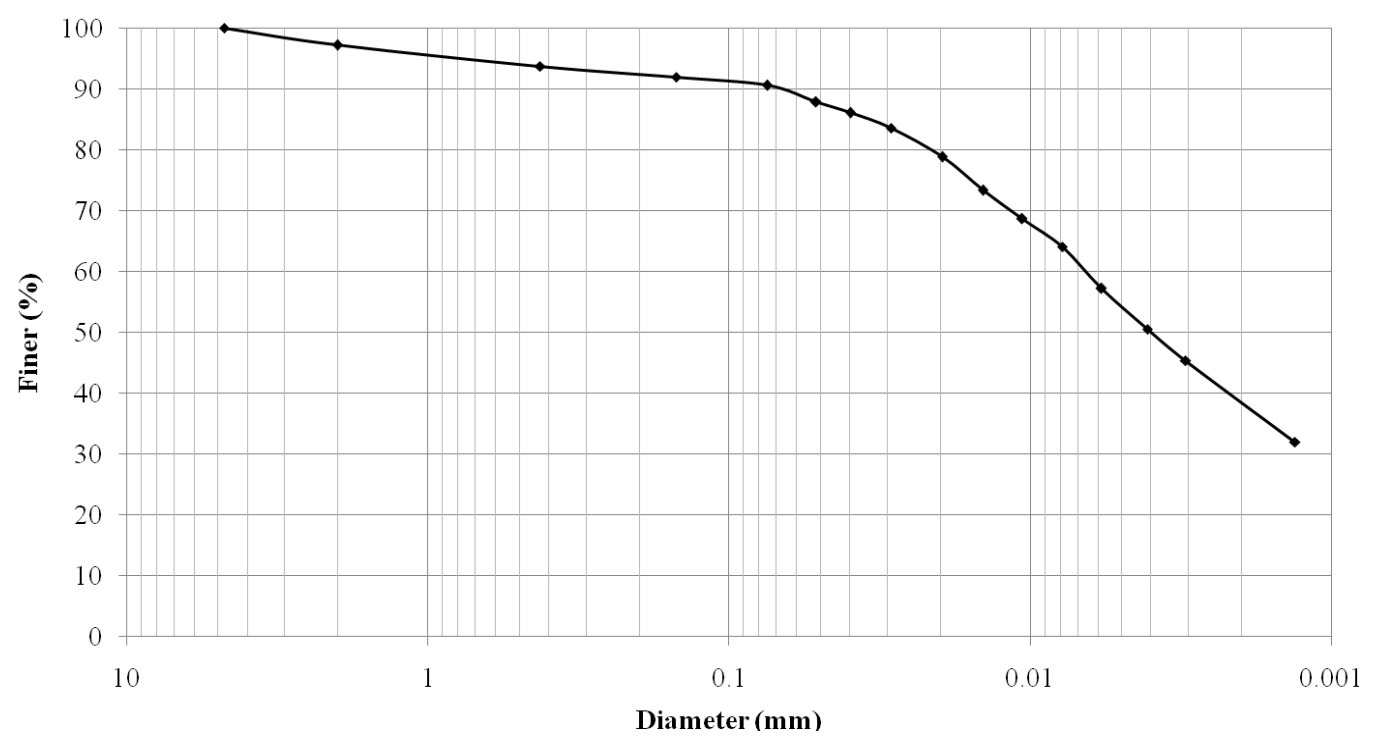

Fig. 5 Grain size distribution of the soil

passed-through and oven dried were mixed with specific amount of water to obtain identical water content and unit weight of the undisturbed samples following the procedure suggested by [13]. Compaction was curved out statically with a rate of $(1.27 \mathrm{~mm} / \mathrm{min}$. $)$, to achieve the desired unit weight of the undisturbed specimens. The compaction mold used is shown in Fig. (6), 4 " in diameter by $4.6 "$ in height $(101.6 \times 116 \mathrm{~mm})$ to retrieve the compacted specimens from this mold. The specimen is compacted from the top to the half determinate distance, and then it is reversing to complete the compaction process from the bottom. This procedure is suggested to ensure obtaining homogeneous compacted specimens, (compaction process consisting with several layers the density will be not homogeneous, where the soil in the lower part of the compacted specimen is probably denser than the soil in the upper part since the lower part receives compactive energy from each overlying lift) [7]. After compaction process the specimens of SWCC, unsaturated coefficients of permeability and diffusion were obtained in the above mentioned directions from the center of the mold.

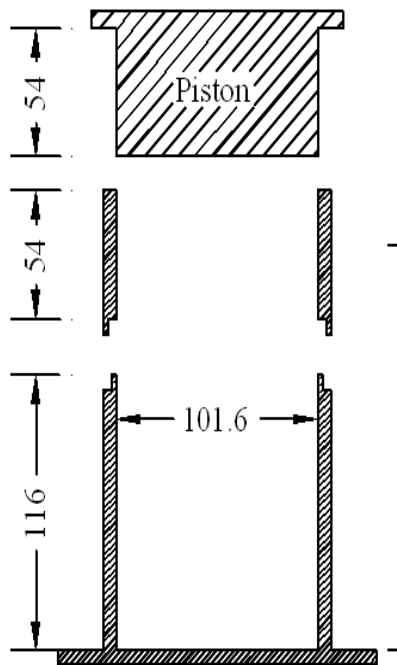

Step
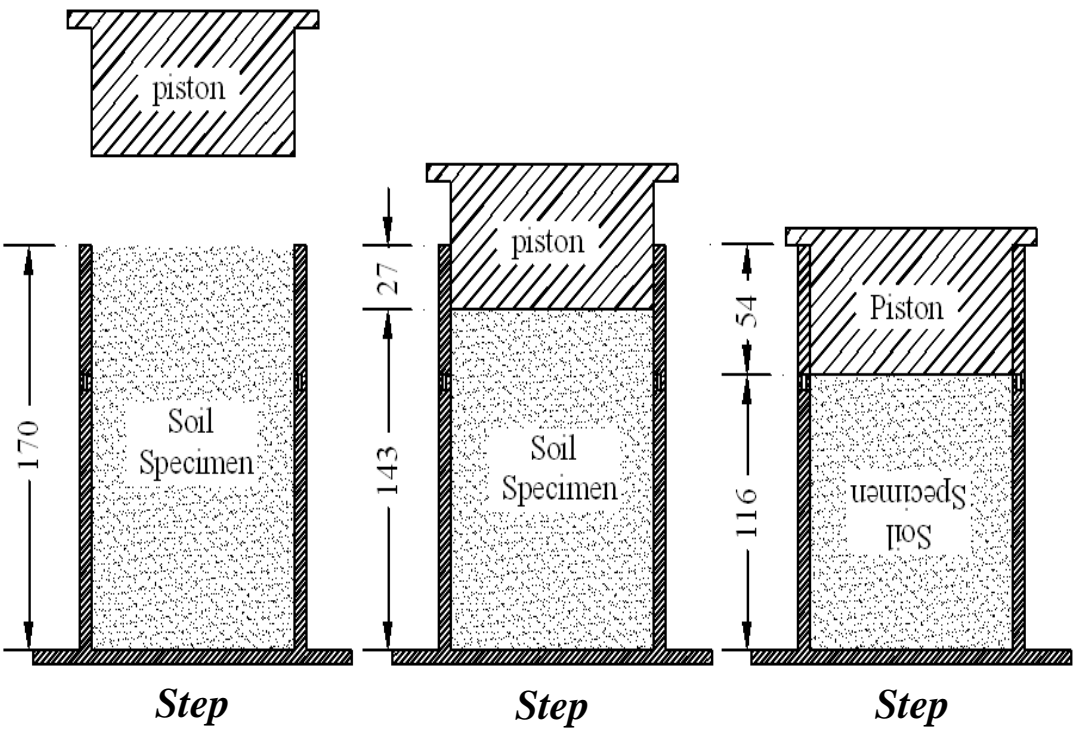

Fig. 6 Compaction mold (Dimensions 


\section{Results \& discussion}

\section{- Soil water characteristic curve}

Fig. (7) and table (4) show the effect of anisotropy on the soil water characteristic curves behaviour for both disturbed and undisturbed soil specimens. Statistical mean values

Table(4): Mean values of the volumetric water content and the state of anisotropy

\begin{tabular}{|c|c|c|c|c|c|c|}
\hline \multirow{2}{*}{$\begin{array}{l}\text { State } \\
\text { of } \\
\text { soil }\end{array}$} & \multirow{2}{*}{$\begin{array}{c}\text { Soil } \\
\text { suction } \\
(\mathrm{kPa}) \\
\end{array}$} & \multicolumn{3}{|c|}{ Volumetric water content $\left(\theta_{m}\right)$} & \multirow[t]{2}{*}{$\overline{\theta_{m i} / \theta_{m v}}$} & \multirow[t]{2}{*}{$\theta_{m h} / \theta_{m v}$} \\
\hline & & $\theta=0^{\circ}(\mathrm{V})$ & $\theta=45^{\circ}(\mathrm{I})$ & $\theta=90^{\circ}(\mathrm{H})$ & & \\
\hline \multirow{12}{*}{ 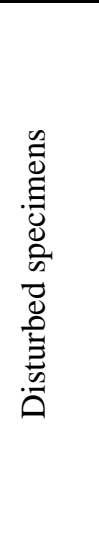 } & 1 & 31.970 & 30.471 & 29.022 & 0.953 & 0.908 \\
\hline & 10 & 31.262 & 29.769 & 28.330 & 0.952 & 0.906 \\
\hline & 200 & $28.492 \pm 0.087$ & $27.076 \pm 0.030$ & $25.773 \pm 0.053$ & $0.950 \pm 0.002$ & $0.905 \pm 0.001$ \\
\hline & 800 & $23.929 \pm 0.023$ & $22.649 \pm 0.035$ & $21.559 \pm 0.049$ & $0.947 \pm 0.001$ & $0.901 \pm 0.001$ \\
\hline & 2728 & $18.394 \pm 0.054$ & $17.297 \pm 0.069$ & $16.647 \pm 0.089$ & $0.940 \pm 0.001$ & $0.905 \pm 0.002$ \\
\hline & 20364 & $10.523 \pm 0.056$ & $9.935 \pm 0.073$ & $9.586 \pm 0.039$ & $0.944 \pm 0.002$ & $0.911 \pm 0.001$ \\
\hline & 37055 & $8.582 \pm 0.076$ & $8.182 \pm 0.080$ & $7.844 \pm 0.048$ & $0.953 \pm 0.001$ & $0.914 \pm 0.003$ \\
\hline & 56104 & $7.260 \pm 0.086$ & $7.021 \pm 0.091$ & $6.714 \pm 0.040$ & $0.967 \pm 0.001$ & $0.925 \pm 0.005$ \\
\hline & 80721 & $6.214 \pm 0.093$ & $6.026 \pm 0.069$ & $5.872 \pm 0.051$ & $0.970 \pm 0.004$ & $0.945 \pm 0.006$ \\
\hline & 149694 & $4.495 \pm 0.031$ & $4.390 \pm 0.067$ & $4.342 \pm 0.042$ & $0.977 \pm 0.008$ & $0.966 \pm 0.003$ \\
\hline & 286282 & $2.792 \pm 0.029$ & $2.765 \pm 0.035$ & $2.739 \pm 0.021$ & $0.990 \pm 0.002$ & $0.981 \pm 0.003$ \\
\hline & 1000000 & 0.000 & 0.000 & 0.000 & $\begin{array}{ll}--- \\
\end{array}$ & --- \\
\hline \multirow{12}{*}{ 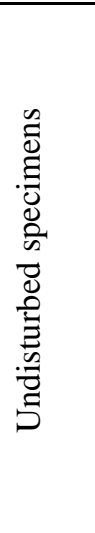 } & 1 & 29.792 & 27.487 & 26.196 & 0.923 & 0.879 \\
\hline & 10 & 28.980 & 26.872 & 25.532 & 0.927 & 0.881 \\
\hline & 200 & $26.554 \pm 0.042$ & $24.788 \pm 0.072$ & $23.219 \pm 0.065$ & $0.933 \pm 0.002$ & $0.874 \pm 0.001$ \\
\hline & 800 & $22.187 \pm 0.059$ & $20.748 \pm 0.102$ & $19.763 \pm 0.080$ & $0.935 \pm 0.002$ & $0.891 \pm 0.002$ \\
\hline & 2728 & $17.030 \pm 0.060$ & $15.684 \pm 0.086$ & $15.233 \pm 0.047$ & $0.921 \pm 0.002$ & $0.895 \pm 0.001$ \\
\hline & 20364 & $9.694 \pm 0.061$ & $9.013 \pm 0.093$ & $8.666 \pm 0.081$ & $0.930 \pm 0.004$ & $0.894 \pm 0.003$ \\
\hline & 37055 & $7.849 \pm 0.042$ & $7.455 \pm 0.079$ & $7.204 \pm 0.056$ & $0.950 \pm 0.005$ & $0.918 \pm 0.002$ \\
\hline & 56104 & $6.717 \pm 0.041$ & $6.417 \pm 0.066$ & $6.115 \pm 0.081$ & $0.955 \pm 0.004$ & $0.910 \pm 0.007$ \\
\hline & 80721 & $5.748 \pm 0.044$ & $5.524 \pm 0.039$ & $5.360 \pm 0.090$ & $0.961 \pm 0.001$ & $0.933 \pm 0.008$ \\
\hline & 149694 & $4.157 \pm 0.029$ & $4.044 \pm 0.023$ & $3.938 \pm 0.013$ & $0.973 \pm 0.001$ & $0.947 \pm 0.004$ \\
\hline & 286282 & $2.579 \pm 0.020$ & $2.560 \pm 0.038$ & $2.489 \pm 0.026$ & $0.993 \pm 0.007$ & $0.965 \pm 0.003$ \\
\hline & 1000000 & 0.000 & 0.000 & 0.000 & ---- & ---- \\
\hline
\end{tabular}

of the volumetric water content $\left(\theta_{m}\right)$ were listed with the standard deviation. The coefficients of anisotropy in terms of inclined and horizontal to vertical volumetric water content $\left(\theta_{m i} / \theta_{m v}\right.$ $\left.\& \theta_{m h} / \theta_{m v}\right)$ respectively, are also listed in the table. The SWCCs were fitted by Fredlund and Xing models [9]. The results indicated that this model can be better fit SWCC. The fitting parameters are shown in table (5) with the statistical indicators. Fredlund and Xing (1994) model equation can be expressed in the following form:

$$
\theta=\theta_{s} \cdot\left[1-\frac{\ln \left[1+\left(\frac{\psi}{\psi_{r}}\right)\right]}{\ln \left[1+\left(\frac{10^{6}}{\psi_{r}}\right)\right]}\right] \cdot\left[\frac{1}{\ln \left[e+\left(\frac{\psi}{a}\right)^{n}\right]^{m}}\right]
$$

Where: 
$\theta=$ volumetric water content

$\theta \mathrm{s}=$ saturated water content $($ volumetric water content at suction $=0, \mathrm{kPa})$

$\psi=$ total suction $(\mathrm{kPa})$

$\psi_{\mathrm{r}}=$ residual suction $(\mathrm{kPa})$

$e=2.71828$

$a, n, m=$ model parameters

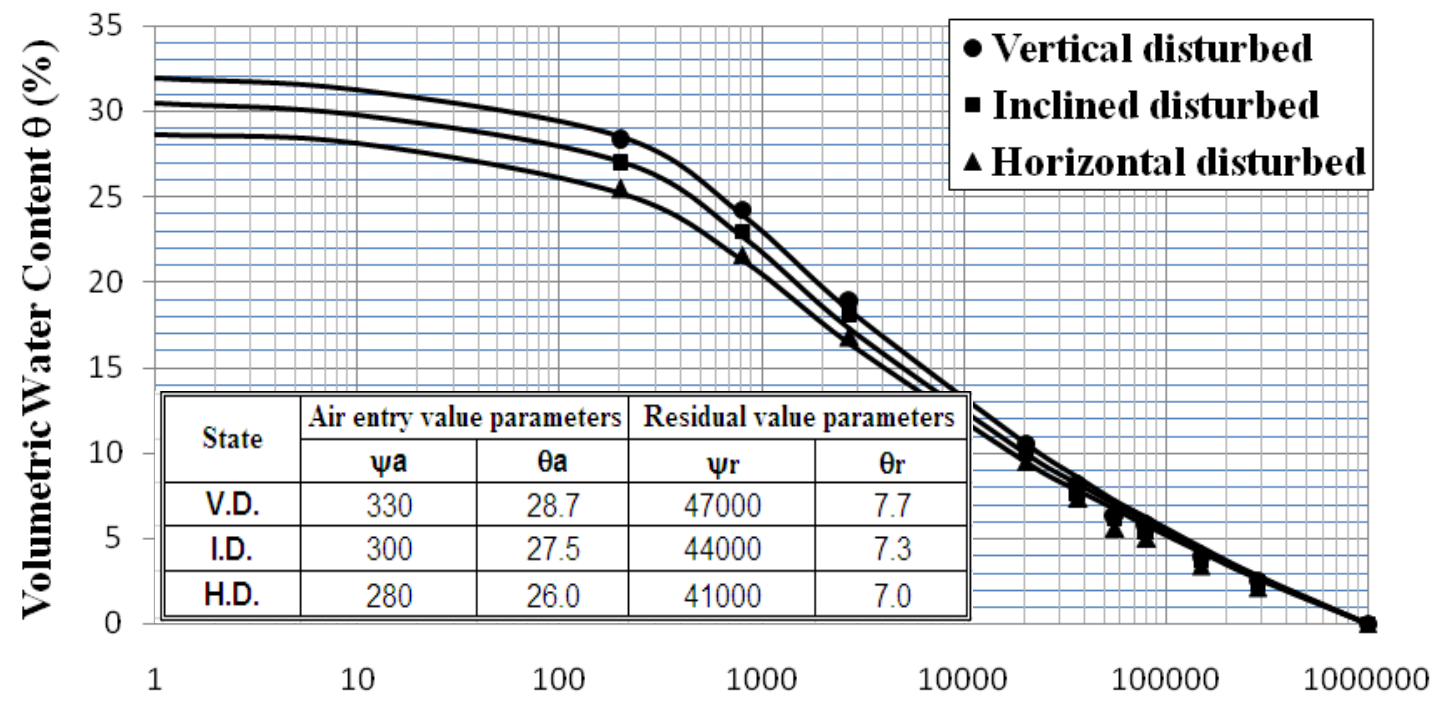

Total Suction $\Psi(\mathbf{k P a})$

-a-

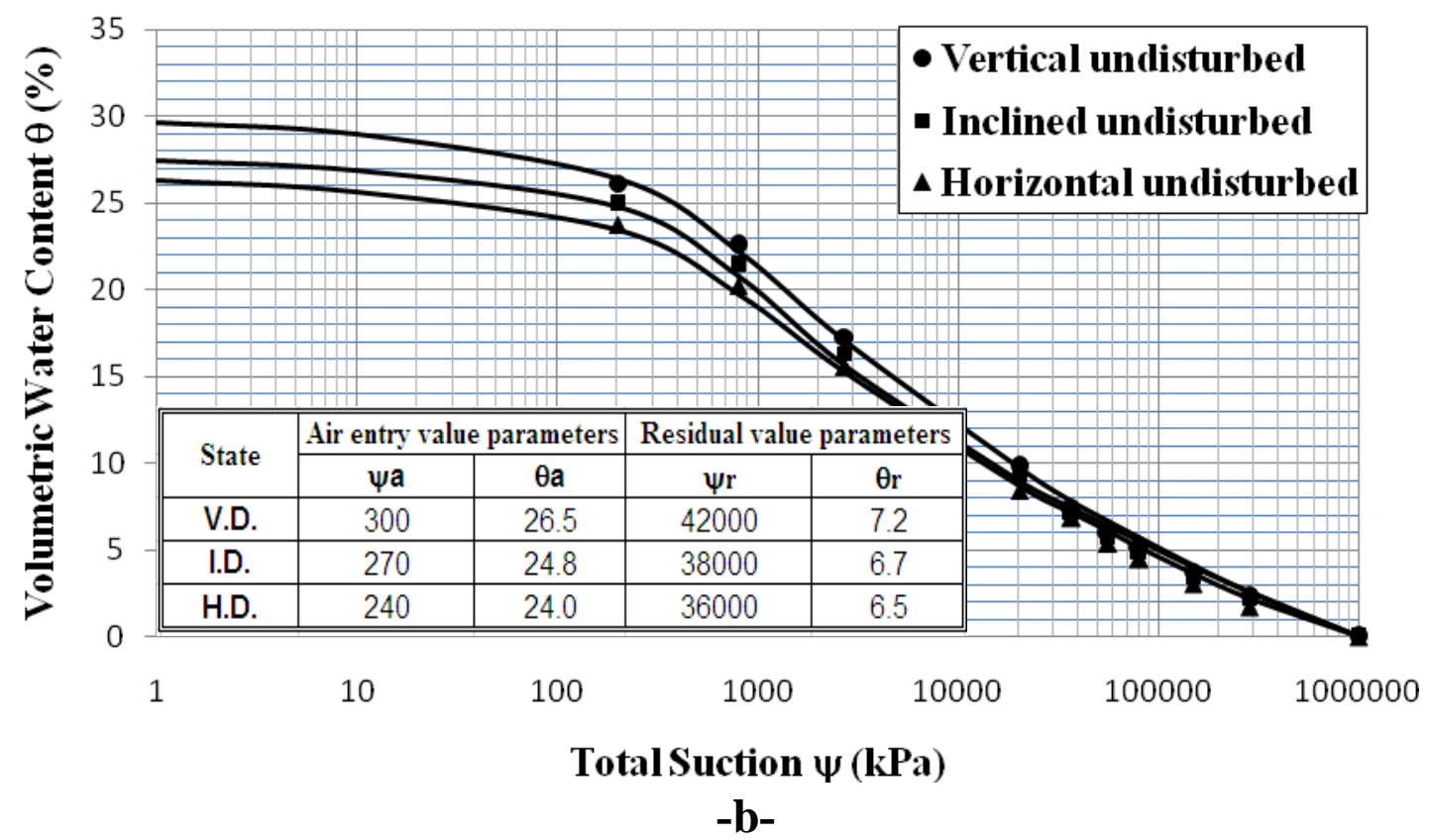

Fig. 7 Effect of anisotropy on soil water characteristic curve, a- Disturbed specimens, b- Undisturbed specimens

It is obvious from Fig. (7) that the SWCC for the specimen retrieved in the vertical direction has more an air-entry suction value $\left(\psi_{\mathrm{a}}\right)$, and the curve appears to be slightly steeper comparing with the other directions. Hence, the SWCC in the vertical direction has more ability to store water. This can be explained by the inter-particles bond between the soil 
particles in this direction which is might be more connected with each other than the particles in the other directions. This behaviour of the SWCC is evident at low suction, and it could be noticed that the effect of anisotropy was diminished with increase of suction and the curves seem to be identical with each other. In the other side, the effect of anisotropy on the SWCC behaviour was more evident on the undisturbed soil specimens than the disturbed ones. This is due to the preferred horizontal alignment of the soil particles during deposition and subsequent consolidation under the overburden weight which makes the undisturbed specimens more cross anisotropic than the disturbed specimens [17].

Table (5): Soil water characteristic curve fit parameters and the statistical indicators

\begin{tabular}{|c|c|c|c|c|c|c|}
\hline \multicolumn{2}{|c|}{ State of soil } & \multicolumn{2}{|c|}{ Fitting parameters } & \multicolumn{2}{c|}{ Statistical indicators } \\
\cline { 3 - 7 } \multicolumn{2}{|c|}{} & $a$ & $n$ & $m$ & $S S R$ & $\boldsymbol{R}^{2}$ \\
\hline \multirow{2}{*}{$\begin{array}{c}\text { Confined } \\
\text { disturbed }\end{array}$} & Vertical & 620 & 0.90 & 0.83 & 4.1655 & $\mathbf{0 . 9 9 8 5 3}$ \\
\cline { 2 - 7 } & Inclined & 600 & 0.90 & 0.84 & 3.8092 & $\mathbf{0 . 9 9 8 5 3}$ \\
\cline { 2 - 7 } & Horizontal & 590 & 0.90 & 0.83 & 2.5082 & $\mathbf{0 . 9 9 8 8 4}$ \\
\hline \multirow{2}{*}{$\begin{array}{c}\text { Confined } \\
\text { undisturbed }\end{array}$} & Vertical & 600 & 0.90 & 0.83 & 2.8386 & $\mathbf{0 . 9 9 8 5 3}$ \\
\cline { 2 - 7 } & Inclined & 600 & 1.00 & 0.77 & 2.9466 & $\mathbf{0 . 9 9 8 7 3}$ \\
\cline { 2 - 7 } & Horizontal & $\mathbf{5 8 0}$ & $\mathbf{0 . 9 0}$ & $\mathbf{0 . 7 8}$ & $\mathbf{1 . 3 3 1 1}$ & $\mathbf{0 . 9 9 9 1 4}$ \\
\hline
\end{tabular}

Fig. (8) shows the difference between the soil water characteristic curve behaviour for disturbed and undisturbed specimens, (i.e., the effect of disturbance on the SWCC behaviour). It could be noticed from the Fig. that the soil water characteristic curve for the disturbed specimens is above and more steeper than that one for undisturbed specimens for the whole range of the soil suction, although the difference is more evident at the low values of soil suction. This can be explained as the static compaction of the soil specimens affects and destroyed the most of macropores existing between clods. Hence, in this state the pore size distribution is may be more regular and the microscale pores is predominant, which have more ability to store the water, and more air-entry value of suction. This behaviour agrees with the results of researchers [12], [15] and [3].

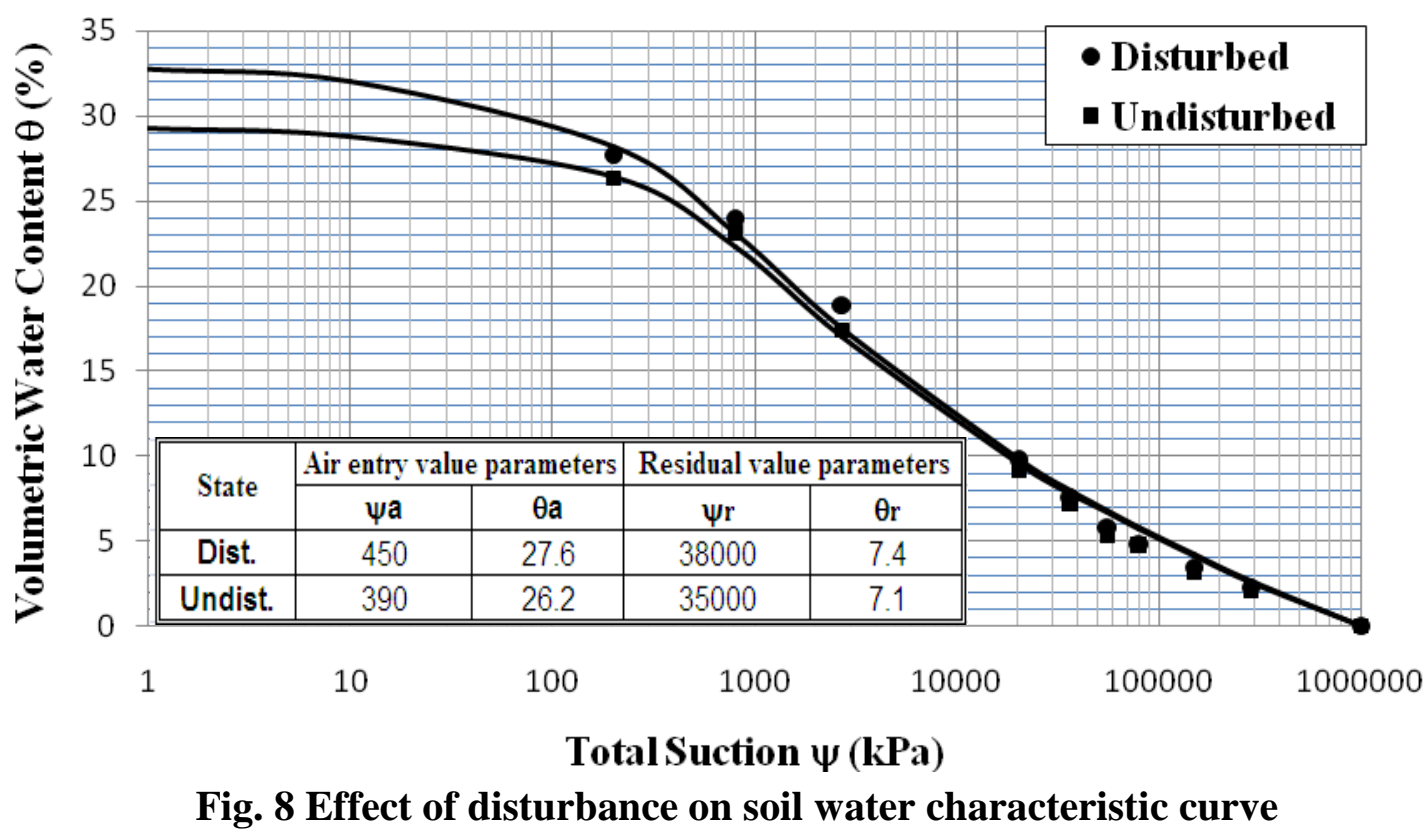




\section{- Coefficients of diffusion and permeability}

Figs. (9-12) show the effect of anisotropy on unsaturated coefficients of permeability and diffusion behaviour with time at different values of suction gradient, for both disturbed and undisturbed soil specimens. It is obvious from the Figs. that both of coefficients of permeability and diffusion values at beginning drops quickly after a short time, followed by a gradually decrease until reaching an equilibrium state. This is due to the quick transfer of water vapor at the beginning because the large difference in the relative humidity (R.H.) at the

two sides of the sample which gradually decreases with time. This behaviour agrees with the results of [6] \& [2].

The differences between unsaturated coefficients of permeability and diffusion in the three mentioned directions are more evident at low suction gradient than that at high suction gradient. Comparing between unsaturated coefficients of permeability and diffusion for both disturbed and undisturbed soil specimens, the values for the latter were greater than that for disturbed specimens. Furthermore the unsaturated coefficients of permeability and diffusion for horizontal retrieved specimens were greater than that prepared in the other directions $\left(45^{\circ}\right.$ inclined and vertical directions). This can be explained as the water vapor transfer in this direction might be occurred parallel to the bedding planes which facilitate the moisture movement.

Figs. (13 and 14) show the effect of suction gradient on unsaturated coefficients of permeability and diffusion respectively. It is obvious from the Figs. that when suction increases, the diffusivity increases too but the coefficient of permeability decreases. This behaviour could be attributed to the processes of water transfer and to the accessibility of the vapor through the porous phase. Decreasing suction induces an adsorbed water layers of certain thickness, which could be fixed within the interstitial pores, and when suction becomes sufficiently weak, the phenomenon of capillary condensation occurs which fills the finest pores and so obstructs the direct passage of the vapor. This reduces the available porosity and vapor diffusion and increases the coefficient of permeability.

The variations of hydraulic conductivity and vapor diffusivity versus suction gradient are opposite. With the increase of suction gradient rate, the vapor diffusivity increases while hydraulic conductivity decreases. This could be explained by the progressive change of behaviour during the suction gradient increasing, at high suction gradient, i.e. low relative humidity, most of the moisture moves by diffusion of vapor, and as relative humidity rises, the transport becomes a combination of diffusion, evaporation, condensation and convection. This behaviour agrees with the results of [6]. The hydraulic conductivity increases strongly at low suction gradient, i.e. near high humidity $(\mathrm{RH}>90 \%)$, and the variations can be several orders of magnitude until the value of permeability is reaching the saturation state. 

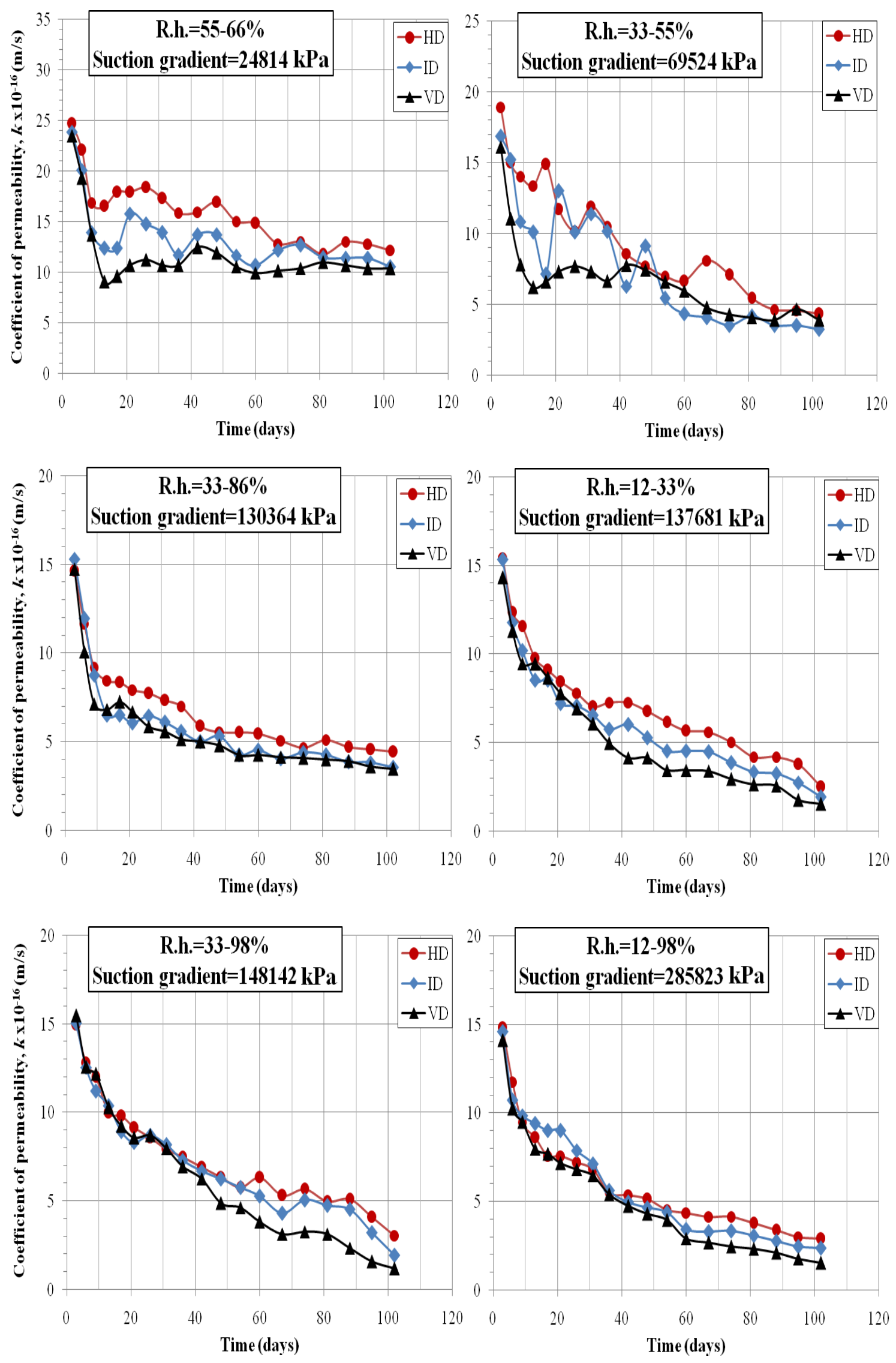

Fig. 9 Effect of anisotropy on unsaturated coefficient of permeability with time at different values of suction gradient, for disturbed specimens 

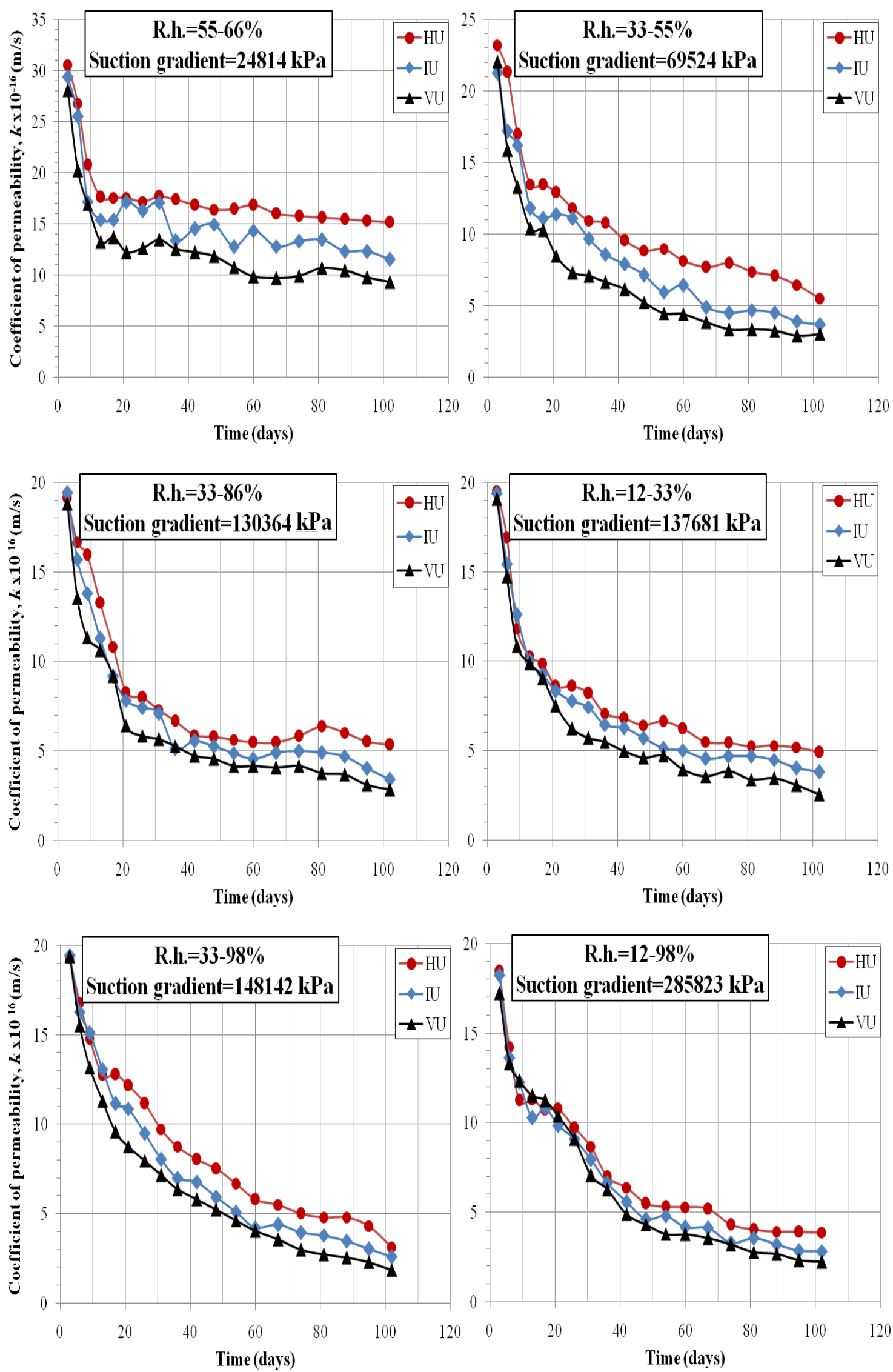

Fig. 10 Effect of anisotropy on unsaturated coefficient of permeability with time at different values of suction gradient, for undisturbed specimens 

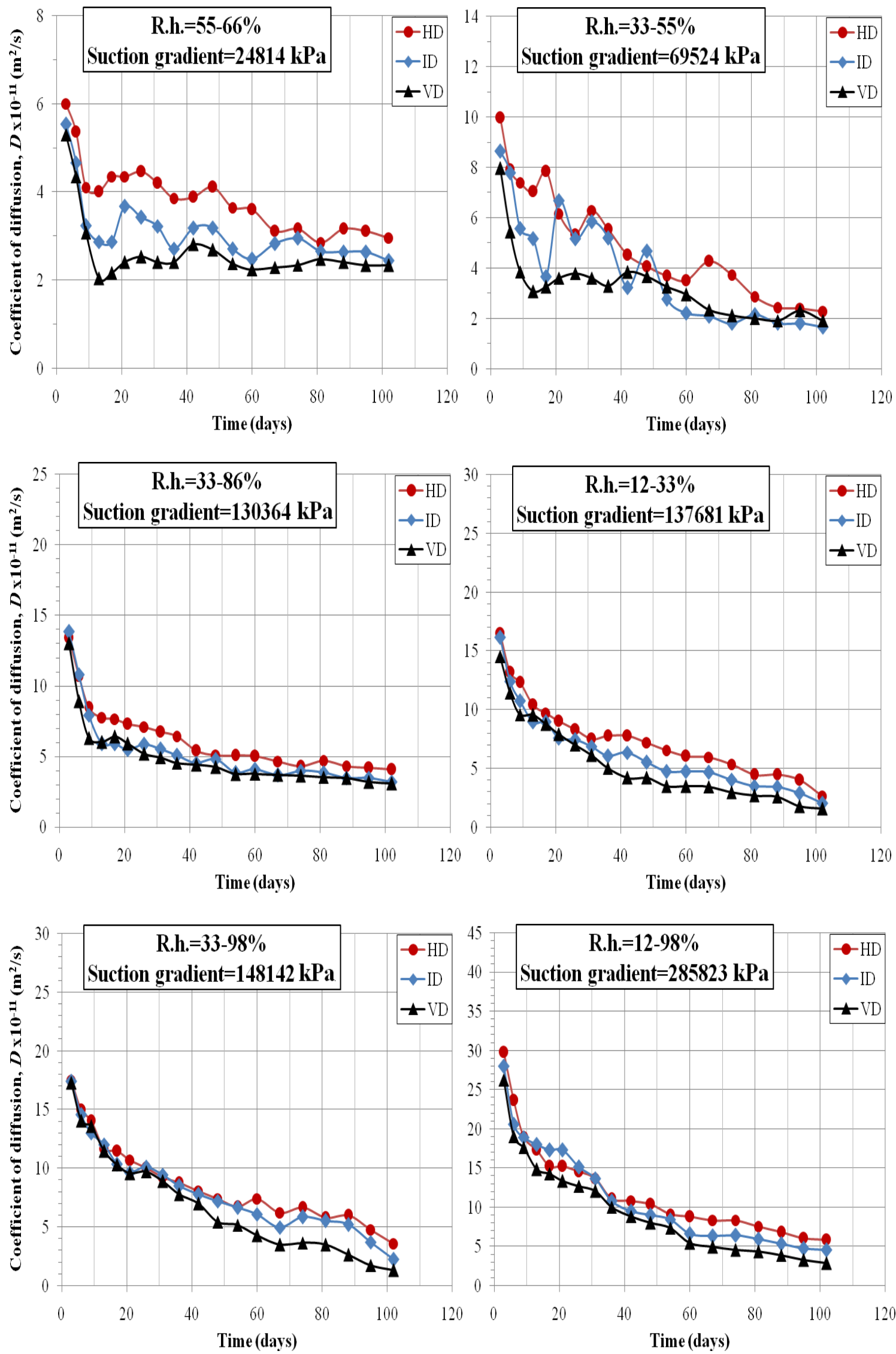

Fig. 11 Effect of anisotropy on coefficient of diffusion with time at different values of suction gradient, for disturbed specimens 

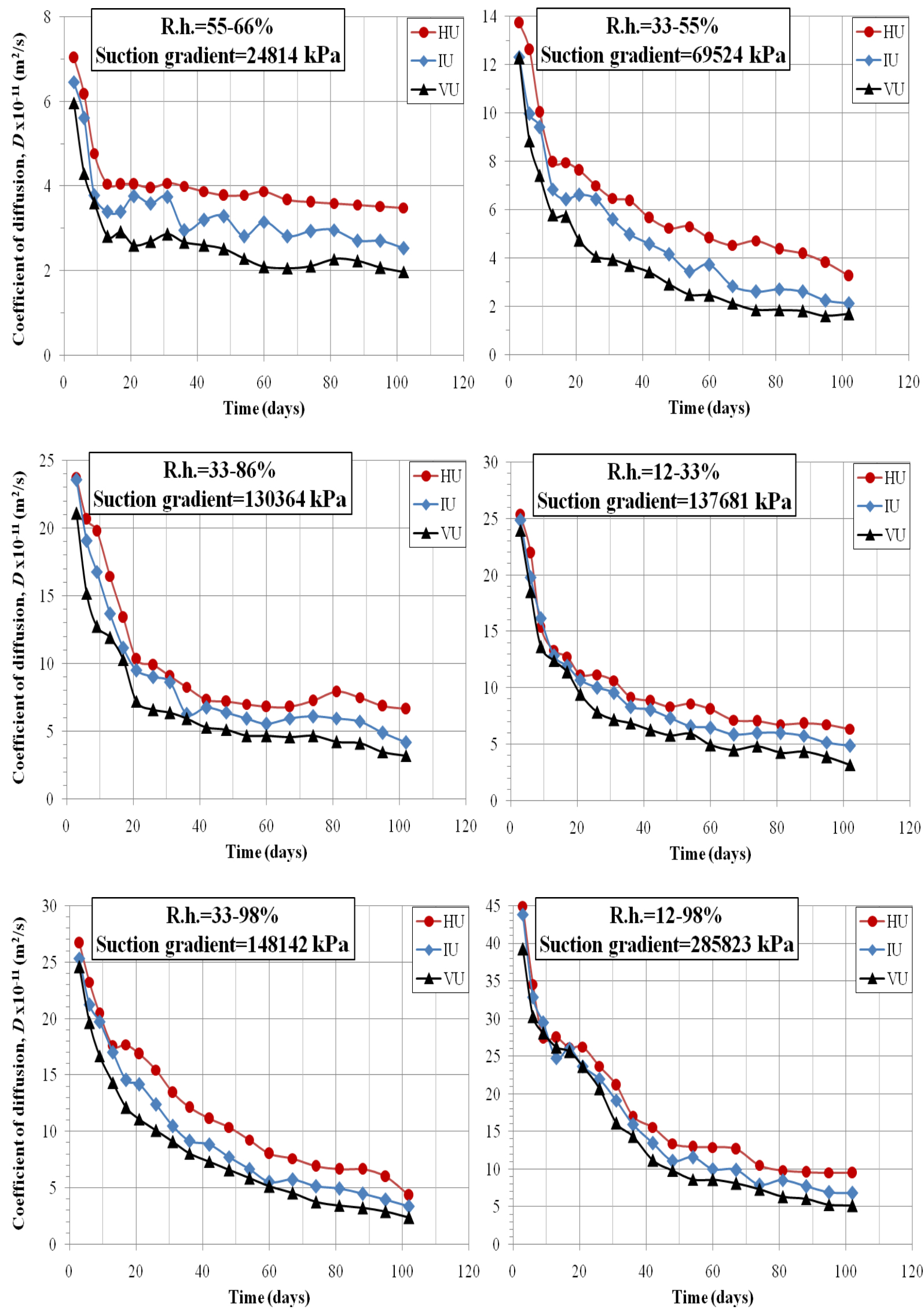

Fig. 12 Effect of anisotropy on coefficient of diffusion with time at different values of suction gradient, for undisturbed specimens 

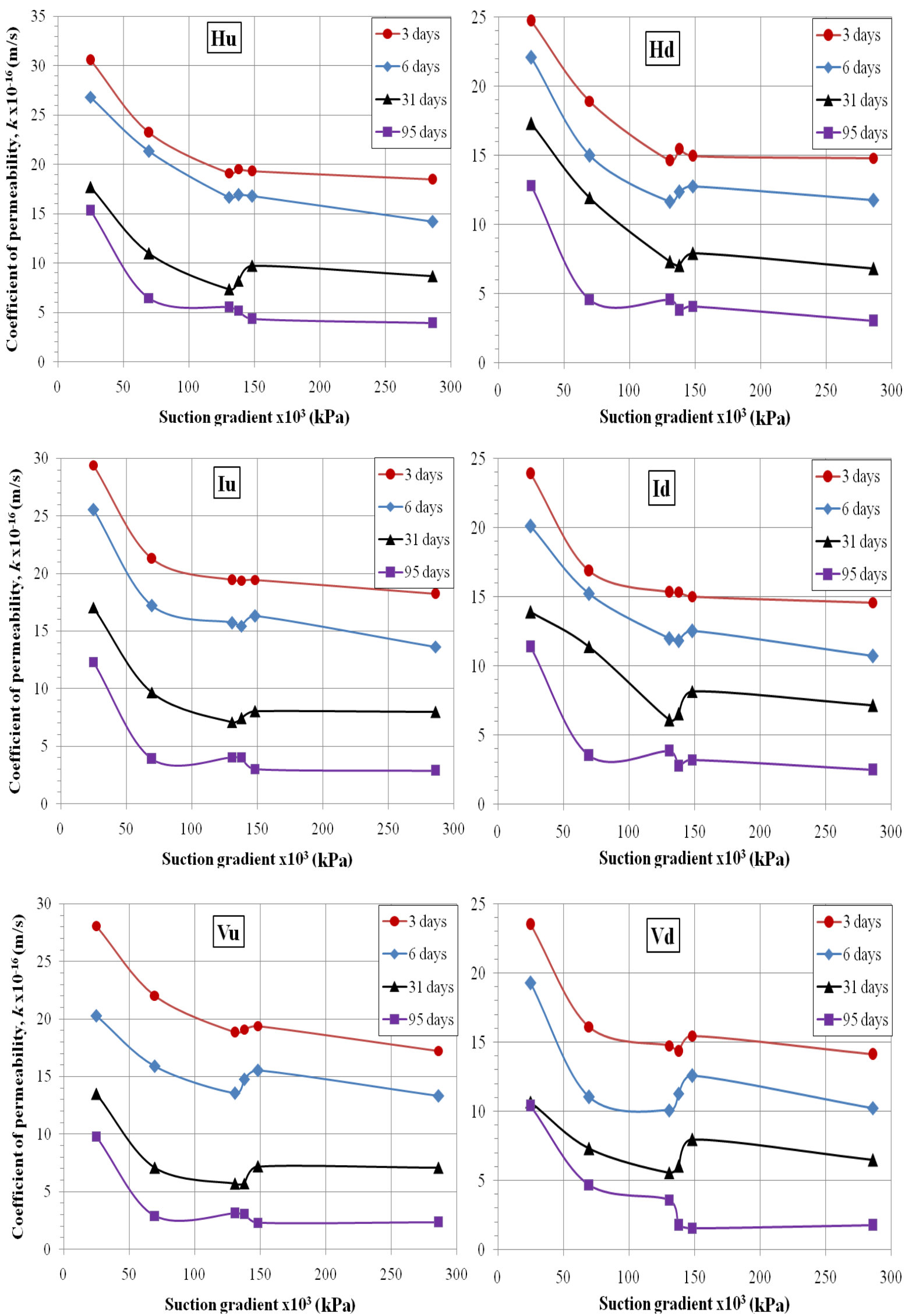

$-b-$

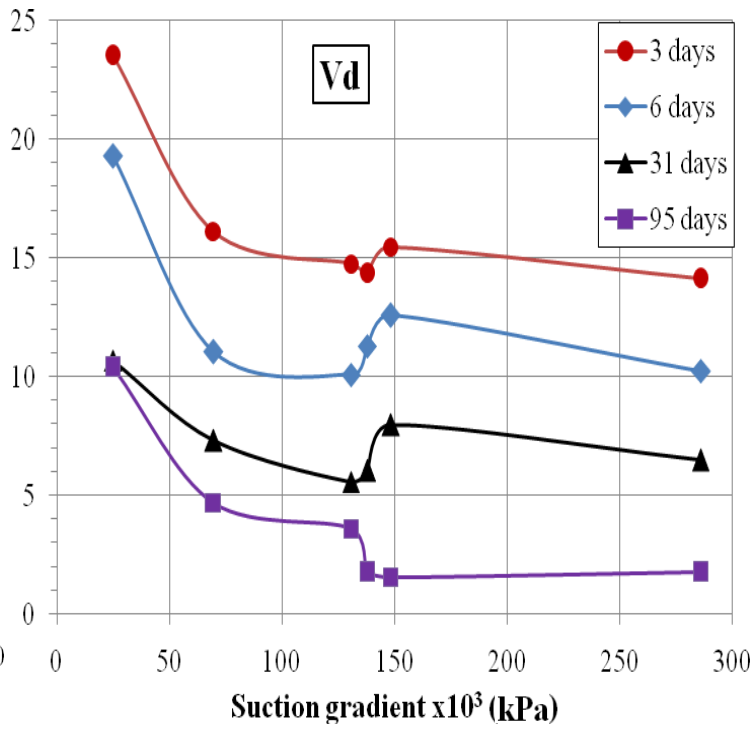

$-\mathbf{a}-$

Fig. 13 Effect of suction gradient on unsaturated coefficient of permeability for a- disturbed specimens, b-undisturbed specimens 

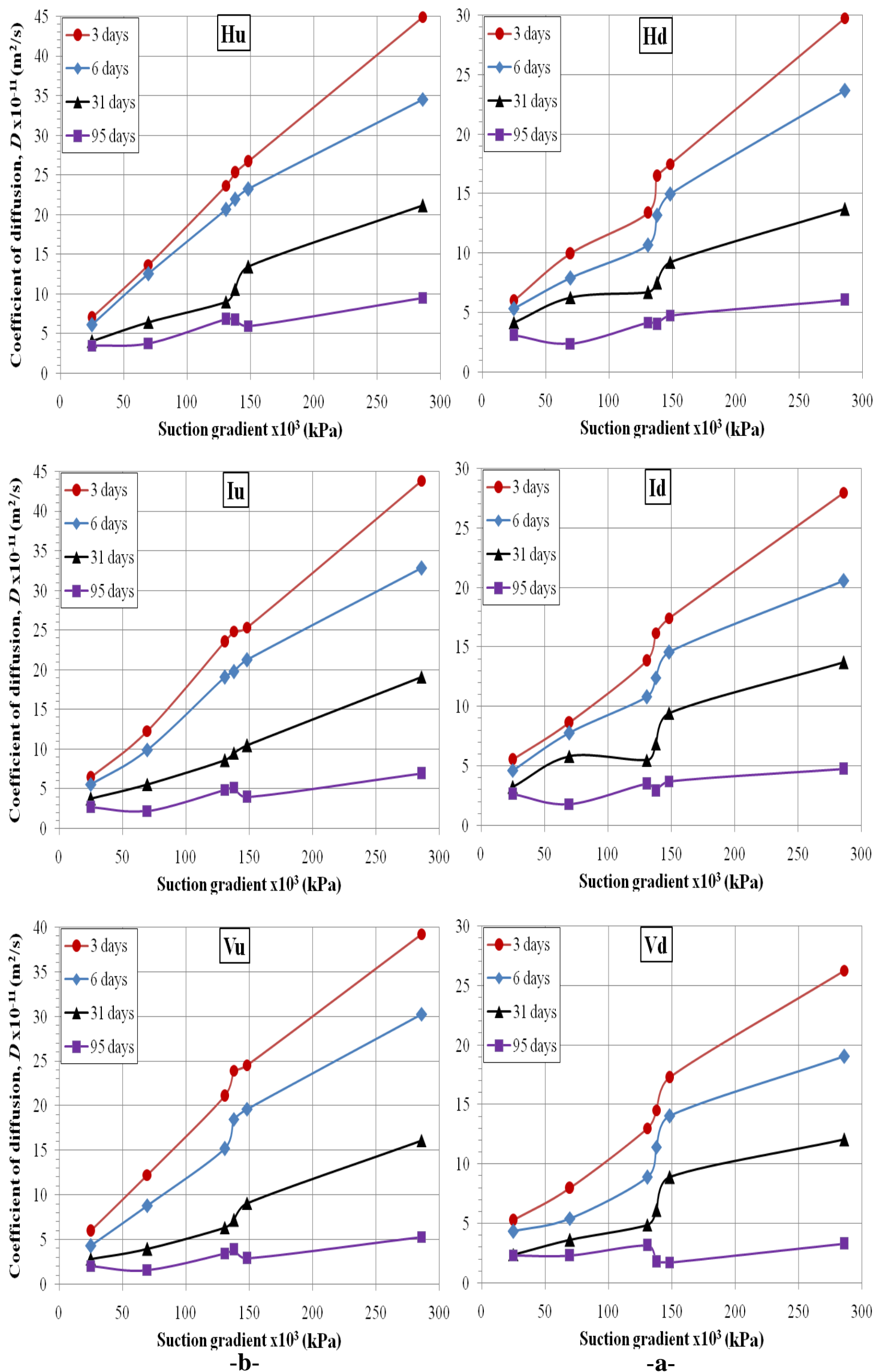

Fig. 14 Effect of suction gradient on unsaturated coefficient of diffusion for 


\section{Conclusions}

From the results of the tests described in this paper, a number of conclusions can be reached regarding the effects of certain testing conditions on the observed SWCC, unsaturated coefficients of permeability and diffusion.

1. There is a limited effect for the anisotropy on the soil water characteristic curve behaviour. The specimen retrieved in the vertical direction has a higher ability to store water and air-entry value suction than any other direction.

2. The soil water characteristic curve for the disturbed specimens is above and more steeper than that one for undisturbed specimens for the whole range of the soil suction, but the difference is shown to be more evident at low suction values.

3. There is a limited effect for the anisotropy on the unsaturated coefficients of permeability and diffusion. The difference in the three studied directions is more evident at low suction gradient than that at high suction gradient.

4. The variations of hydraulic conductivity and vapor diffusivity versus suction gradient are opposite, with the increase of suction gradient rate, the vapor diffusivity increases while hydraulic conductivity decreases.

\section{References:}

[1] Abrisqueta, J.M., Plana, V., Canales, A.R., and Sanchez, M.C.R., (2006). "Unsaturated hydraulic conductivity of disturbed and undisturbed loam soil". Spanish journal of agriculture research, Vol.4, No.1, P.P. 91-96.

[2] Al-Dabbagh ,A.W.N. (2009). "Diffusion and permeability of partially saturated untreated and lime treated gypseous soil". Ph.D. Thesis. College of Engineering, University of Mosul.

[3] Al-Omary, A.M.A. (2007)."Effect of soil type and compaction condition on the behavior of soil water characteristic curve for soils selected from Mosul". M.Sc. Thesis. College of Engineering, University of Mosul.

[4] Al-Taie, L. Kh. I. (2005). "Correlation between suction and some engineering properties of lime stabilized clayey soil from Mosul city". M.Sc. Thesis, College of Engineering, University of Mosul.

[5] ASTM Standard (2003) Annual Book of American society for Testing and Material.

[6] Beck K., Al-Mukhtar M, Rozenbaumb O. and Rautureau M. (2003). "Characterization, water transfer properties and deterioration in tuffeau building material in the Loire valleyFrance". Building and Environment Vol.38, P.P.1151-1162.

[7] Boynton S.S. and Daniel D.E., (1985)."Hydraulic Conductivity Tests on Compacted Clay", Journal of Geotechnical Engineering, ASCE, Vol.111, No.4, P.P.465-478.

[8] Fredlund, D.G. and Rahardjo, H., (1993). "Soil Mechanics for Unsaturated Soils". John Wily \& Sons, Inc., USA.

[9] Fredlund, D.G. and Xing, A., (1994). "Equations for the Soil-Water Characteristic Curve". Canadian Geotechnical Journal, Vol. 31, N0.3: 521-532.

[10] Gao Z. , Zhao J. and Yao Y., (2010), "A generalized anisotropic failure criterion for geomaterials", International Journal of Solids and Structures Vol 47,P.P.3166-3185.

[11] Gao, Ling-xia., Luan, Mao-tian. and Yang, Qing., (2008). "Experimental Study on Permeability of Unsaturated Remolded Clay". Journal of Geotechnical and Geoenvironmental Engineering,Vol.13, P.P.1-14.

[12] Gerscovich, D.M.S. and Sayao, A.S.F.G., (1994)."Evaluation of The Soil-Water Characteristic Curve Equation for Soil from Brazil". Proceedings of $3^{\text {rd }}$ Int. Conf. on Unsaturated Soils 10-13 march, Recife-Brazil, Vol. 1, P.P. 295-300. 
[13] Islam, M.S. and Hoque E., (2003), "Directional Dependency of Strength in Compacted Dhaka Clay", Journal of Civil Engineering, The Institute of Engineering, Bangladesh Vol. CE 31, No. 1, P.P. 25-35.

[14] Khattab, S. A. A. (2002). "Eude Multi-echelles d'un Sol Plastique Traite' a' la Chaux". Ph.D Thesis, University of Orleans, France.

[15] Melgarejo, M.L., Ridley, A.M., and Dineen, K., (2002), "A Comparison of The Soil Water Characteristic Curve for Reconstituted and Undisturbed Sample of a Colluvium from Rio de Janeiro", The $3^{\text {rd }}$ International conference on unsaturated soils 10-13 March, Recife, Brazil, Vol. 2, pp.313-316.

[16] Nishimura S., (2005), "Laboratory Study On Anisotropy Of Natural London Clay", M.Sc. Thesis, Department Of Civil And Environmental Engineering, Imperial College London. [17] O'kelly, B.C., (2006), "Compression and Consolidation Anisotropy of Some Soft Soils", Geotechnical and Geological Engineering, Vol. 24, P.P. 1715-1728.

[18] Vanapalli, S.K. and Lobbezoo, J.P., (2002). "A Normalized Function for Predicting the Coefficient Permeability of Unsaturated Soils". The 3rd International conference on unsaturated soils. Recife, Brazil ed J.F.T. Juca, et al., Balkema Publishers. 